term is losing relevance. Infectious diseases needs strengthening as a clinical specialty in Europe and should encompass parasitic and sexually transmitted diseases, as well as travel medicine. Since infectious diseases are more prevalent in underprivileged communities, experience in resource poor settings should be considered important.

The question of the role and future of clinical services in resource poor countries is more relevant than the future of tropical medicine itself as a discipline. In developing countries, defining what constitutes appropriate services and working to provide them should be seen as the real challenge for medicine in the tropics. If account is not taken of today's changed realities, the continued decline of tropical medicine as understood in Europe seems inevitable.

1 Cook GC. Evolution: the art of survival. Trans $R$ Soc Trop Med Hyg 1994;88: 4-18

2 Waugh MA. History of clinical developments in sexually transmitted diseases. In: Holmes KK, Mardh P-A, Sparling PF, Wiesner PJ, eds. Sexually In: Holmes KK, Mardh P-A, Sparling PF, Wiesner PJ, eds.

3 De Cock KM. Personal view. BMF 1983;287:1139.

4 Kennedy P. Preparing for the twenty-first century. London: Fontana Press, 1993.

5 Centers for Disease Control and Prevention. Addressing emerging infectious disease threats: a prevention strategy for the United States. Atlanta: US Department of Health and Human Services, Public Health Service, 1994.

6 Centers for Disease Control and Prevention. Update: cholera-western hemisphere, 1992. MMWR 1993;42:89-91.

7 Pacquet C, Van Soest M. Mortality and malnutrition among Rwandan refugee in Zaire. Lancet 1994;344:823-4.
8 Hardy RI, Monisov A, Filatov N. Major epidemic of diphtheria, Russia, 19901993. 43rd Annual Epidemic Intelligence Service Conference, Centers for Disease Control and Prevention, Atlanta, 18-22 April 1994.

9 Dennis DT. Plague in India. Lessons for public health everywhere. $B M \gamma$ 1994;309:893-4.

10 Laga M, Diallo MO, Buve A. Inter-relationship of sexually transmitted diseases and HIV: where are we now? AIDS 1994;8(suppl 1):S119-24.

11 World Health Organisation. TB: a global emergency. Geneva: WHO, 1994

12 United Nations High Commissioner for Refugees. State of the world's refugees: the challenge of protection. New York: Penguin, 1993.

13 Stanley K. Control of tobacco production and use. In: Jamison DT, Mosley WH, Measham AR, Bobadilla IL, eds. Disease control priorities in developing countries. New York: Oxford University Press, 1993:703-23.

14 Walsh JA, Feifer CM, Measham AR, Gertler PJ. Maternal and perinatal health. In: Jamison DT, Mosley WH, Measham AR, Bobadilla $\Omega$, eds. Disease control priorities in developing countries. New York: Oxford University Disease control priorities

15 Stansfield SK, Smith GS, McGreevey WP. Injury. In: Jamison DT, Mosley WH, Measham AR, Bobadilla JL, eds. Disease control priorities in developing countries. New York: Oxford University Press, 1993:609-33.

16 Doucet I. Landmines-comprehensive information pack. London: UK Working Group on Landmines, 1994

17 UNDP/World Bank/WHO Special Programme for Research and Training in Tropical Diseases. Tropical disease research progress 1991-92: elevent programme report of the UNDP/World Bank/WHO Special Programme for Research and Training in Tropical Diseases (TDR). Geneva: WHO, 1993.

18 Warren KS. Tropical medicine or tropical health: the Health Clark Lectures, 1988. Rev Infect Dis 1990;12:142-56.

19 McGregor IA. Patrick Manson 1844-1922: the birth of the science of tropical medicine. Trans Soc Trop Med Hyg 1995;89:1-8.

20 McCord C, Freeman HP. Excess mortality in Harlem. $N$ Engl f Med 1990;322:173-7.

21 World Bank. World Development Report 1993. Investing in health. New York Oxford University Press, 1993.

22 Tropical Health and Education Trust. Annual report 1994. London: The Trust, 1994

(Accepted 26 fune 1995)

\title{
Letter from Ethiopia
}

\section{Harnessing the strengths of the leprosy programme to control tuberculosis}

\author{
Diana N J Lockwood, Paul R Saunderson
}

Tuberculosis remains a leading cause of death in Ethiopia but there is no effective national tuberculosis control programme. By contrast, the leprosy control programme has been very successful, with a 10 -fold reduction in the number of leprosy cases requiring antibacterial treatment, though patients with nerve damage require continuing care. The paradox of rising numbers of tuberculosis cases and declining numbers of leprosy cases may be solved by joint leprosy-tuberculosis clinics. The strengths of leprosy fieldworkers in control management, case holding, and compliance can be harnessed in developing an effective tuberculosis control programme. Implementing a joint programme in Ethiopia may be beneficial not only for tuberculosis patients but also for leprosy patients, who are thus brought closer to general medical services.

The name Ethiopia is for most people in the West synonymous with famine and powerful visual images of starving children and hapless mothers. But it is now 10 years since the last major famine. In 1994 the rains were good, and in most of the country there is little evidence of acute starvation. Nevertheless, persisting poverty is everywhere: many people go barefoot, boys play with footballs made of rags, and cigarette smoking is unknown except among affluent doctors.

The dire economic conditions are reflected in disease patterns. The Ministry of Health's document Health Indicators 1994 shows that infectious diseases accounted for six of the 10 leading causes of inpatient mortality. ${ }^{1}$ Tuberculosis heads the list, causing $15 \cdot 1 \%$ of all hospital deaths $(n=6358)$ and an estimated $30 \%$ of deaths among medical patients. HIV infection is spreading in Ethiopia but has not yet reached the epidemic proportions of neighbouring African states. In the capital, Addis Ababa, HIV infection and tuberculosis are seen as coinfections, accounting for around $40 \%$ of tuberculosis cases. But in rural areas coinfection is less common, though accurate figures are not yet available.

Despite the magnitude of the tuberculosis problem in Ethiopia there is currently no effective national tuberculosis programme. There is no national registration of cases, no nationally agreed treatment regimen, no national monitoring of drug resistance patterns, and no means of ensuring adequate and secure tuberculosis drug supplies to hospitals. The Ministry of Health is well aware of these problems and has been looking for appropriate solutions. One possible solution seems to be emerging from an unexpected source-namely, the national leprosy programme.

\section{Successful leprosy control programme}

With leprosy, unlike tuberculosis, there is a real prospect of disease control. By comparison with tuberculosis programmes, leprosy control has been well funded, mainly by outside agencies. A major step forward in leprosy control has been the introduction of multiple drug therapy, which combines the use of three antileprosy drugs in a defined treatment period (either six or 24 months). This drug combination has produced bacteriological cure in virtually all patients, with relapse rates of only $1 \%$, and so has enabled many leprosy patients to be released from treatment.

As the case load for leprosy fieldworkers declines the 


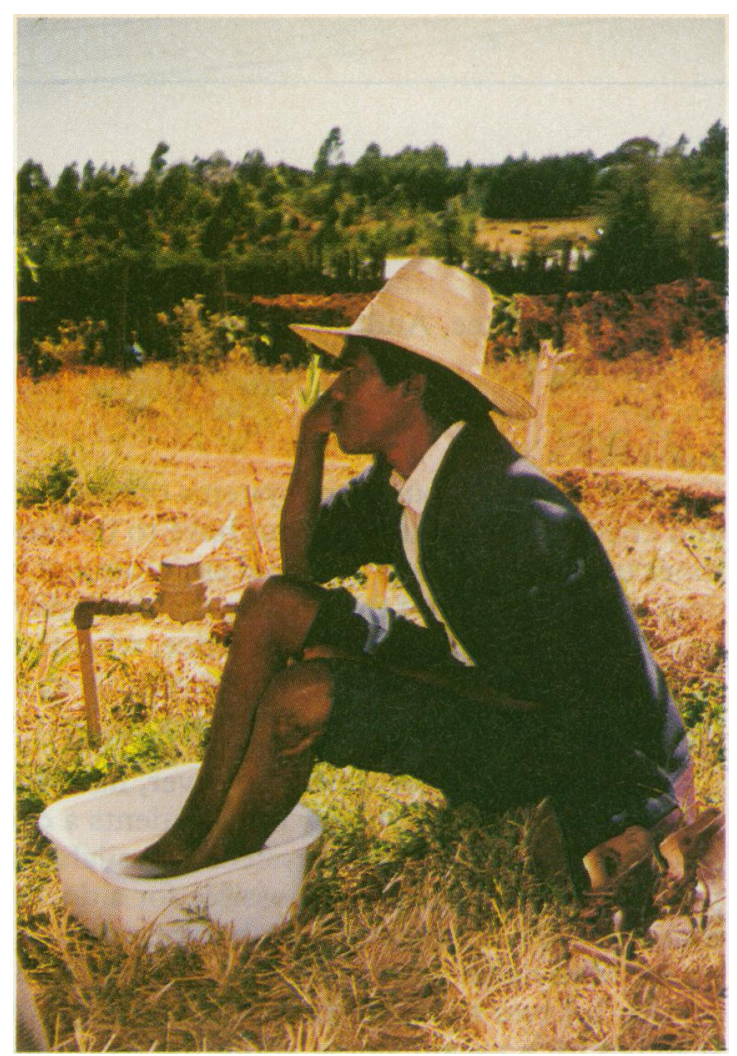

Patient receiving foot care for leprosy. Foint leprosy-tuberculosis clinics may remove the stigma of leprosy treatment

continuing feasibility of such a strong vertical leprosy programme is being questioned, though continued monitoring for new leprosy cases and complications in treated cases is required. Leprosy programmes have a strong tradition of good management with emphasis on case finding and case holding, and it is these strengths that may now be harnessed to control tuberculosis. Combined leprosy and tuberculosis control programmes have been successfully implemented in Tanzania and Uganda.

\section{Joint leprosy-tuberculosis control programme}

In 1993 the Ethiopian Ministry of Health created a joint leprosy and tuberculosis control programme, and the next year the first of these programmes was started. The area chosen was southern Shoa, a densely populated fertile region of Ethiopia with a high incidence of tuberculosis (at least $\mathbf{4 0 0 0}$ smear positive cases a year in a population of 3.2 million) and a large number of health units, both government and missionary. The region had also been the recipient of a World Health Organisation emergency programme for tuberculosis, an initiative that lasted a mere 12 months and produced no infrastructure for the management of tuberculosis. Leprosy control in the area is provided by the All Africa Leprosy Education Rehabilitation and Training Hospital control programme. This programme has nine supervisory staff and seven health assistants, who provide leprosy care in 57 clinics serving 286 registered leprosy patients. Most of these patients live at least two hours' walk from their nearest clinic.

The numbers of leprosy patients in the region requiring antibacterial drugs fell from 2500 in 1984 to 286 in 1994, though the yearly number of new patients remains constant at about 180 . There remain substantial numbers of patients needing long term monitoring and supportive care for the complications of leprosy, such as nerve damage, which persist after bacteriological cure. The region has therefore reached the arbitrary WHO target for the "elimination of leprosy as a public health problem"-namely, a prevalence of less than one case per 10000 population.

It is anticipated that tuberculosis control will be shared between the general health services and the leprosy control programme. Diagnosis and initiation of treatment will be carried out by the general medical services, and responsibility for administering and maintaining treatment will lie with the leprosy control programme. This division of responsibility ensures that tuberculosis remains within the remit of the general medical services while drawing on the management strengths of the leprosy staff in ensuring compliance.

\section{Implementing a new programme}

The initial organisation of the combined programme included repairing the tuberculosis clinic and office in Hosanna, the central town of the area; printing reporting and recording formats; replacing light bulbs in disused microscopes; and ordering drugs and reagents for staining sputum smears. Staff training has been a major component of this initiation phase, special training programmes being organised for laboratory technicians, programme coordinators, and health workers. The training programmes seem to have been very successful, many workers commenting favourably and others clamouring for training. The enthusiasm generated has breathed new life into the leprosy programme, with the supervisors responding to their new dynamic roles.

Problems encountered by the new programme included differing criteria for diagnosing tuberculosis - some units relying primarily on $x$ ray films and the erythrocyte sedimentation rate-and continuing uncertainty over administrative boundaries, with regional, zonal, and district boundaries not yet fully agreed on. Short course chemotherapy regimens are used which do not require hospital admission, though patients need to be seen six times a week for the first eight weeks. This pilot project has been generously funded by the German Leprosy Relief Association, but the high cost of antituberculous drugs is an issue that must be resolved if the scheme is to be introduced on a wider scale.

Will the patients themselves like the new format? Leprosy is currently a highly stigmatised disease in the area, and tuberculosis patients may be reluctant to attend clinics perceived as being only for leprosy. In the short to medium term it will be important to ensure that the needs of leprosy patients with chronic disabilities are not overlooked in the enthusiasm for chasing up tuberculous defaulters. In the long term this joint programme may be the mechanism whereby leprosy patients are recognised as having needs within the remit of the general medical services and so cease to be medically stigmatised.

The initial months of this programme have been encouraging, but clearly only long term evaluation and assessment will show whether this approach of combined management will ensure both good ongoing care for leprosy patients and improvement in the management of tuberculosis.

We thank Dr Mengistu Asnake for the time he spent showing us the combined leprosy-tuberculosis programme.

Funding: DL thanks the Hospital for Tropical Diseases Special Trustees Fund for funding her visit to Ethiopia.

Conflict of interest: None.

1 Ministry of Health. Health indicators 1994. Addis Ababa: MoH, 1994.

(Accepted 29 fune 1995) 